\title{
STUDI KOMPARASI BUDAYA SEKOLAH SDSN DAN SD EKS RSBI DI DAERAH ISTIMEWA YOGYAKARTA
}

\section{A COMPARATIVE STUDY OF SCHOOL CULTURE IN SDSN AND SD EX-RSBI IN YOGYAKARTA SPECIAL TERRITORY}

\author{
Taufik Muhtarom, Muhammad Nur Wangid \\ SD Muhammadiyah Noyokerten Sleman, Universitas Negeri Yogyakarta \\ taufikmuhtarom@gmail.com, nurwangid2003@yahoo.com
}

\begin{abstract}
Abstrak
Penelitian ini bertujuan untuk: (1) mengetahui perbedaan budaya sekolah di SDSN dan SD Eks RSBI DIY, (2) memaparkan perbedaan masing-masing aspek budaya sekolah antara SDSN dengan SD Eks RSBI. Jenis penelitian ini adalah komparasi. Populasi penelitian ini adalah semua kepala sekolah, guru, dan staf SDSN dan SD RSBI di Daerah Istimewa Yogyakarta yang berjumlah 797 orang untuk SDSN dan 155 orang untuk SD Eks RSBI. Sampel dari SDSN berjumlah 256 orang dan sampel dari SD Eks RSBI sebanyak 116 orang ditentukan menggunakan teknik proportional sampling. Pengumpulan data dilakukan menggunakan kuesioner. Teknik analisis data yang digunakan adalah analisis univariat, bivariat, dan uji-t. Hasil penelitian ini menunjukkan bahwa: (1) tidak terdapat perbedaan yang signifikan antara budaya sekolah SDSN dengan SD Eks RSBI di Daerah Istimewa Yogyakarta; (2) ditemukan perbedaan skor dari masing-masing aspek budaya sekolah di SDSN dan SD Eks RSBI DIY. Aspek budaya sekolah yang lebih baik di SDSN adalah kolaborasi profesional, hubungan kolegial, self determination, visi-misi, konsensus, dan disiplin. Sedangkan aspek budaya sekolah yang lebih unggul pada SD Eks RSBI adalah aspek komitmen, hormat, empati, bebas bullying dan artefak fisik.
\end{abstract}

Kata kunci: budaya sekolah, SDSN, SD Eks RSBI

\begin{abstract}
This study aims to: (1) determine the differences of school culture in SDSN and SD Ex RSBI in Yogyakarta Special Territory, (2) describe the differences of each aspect of school culture in SDSN and SD Ex-RSBI in Yogyakarta Special Territory. This is a comparative study. The population was all school principals, teachers, and staff of SDSN and SD Ex-RSBI in Yogyakarta Special Territoy totalling 919 people in SDSN and 237 people in SD Ex-RSBI. A sample of 256 people from SDSN and 116 from SD Ex-RSBI was established using the proportional sampling technique. The data collection used a questionnaire. The data analysis technique used is the univariate, bivariate, and t-test. The results of this study show that: (1) there is no significant difference between the shcool culture in SDSN and SD Ex-RSBI in Yogyakarta Special Territory; (2) there is different scor for each aspect of culture school in SDSN and SD Ex RSBI. The aspect of school culture better in SDSN includes professional collaboration, affiliative collegiality, self-determination, vision and mission, consensus, and discipline. While the aspects of school culture that is better in SD Ex-RSBI are commitment, respect, empathy, free from bullying and physical artifacts.
\end{abstract}

Keywords: school culture, SDSN, SD Ex-RSBI 


\section{Pendahuluan}

Pemerintah melalui berbagai kebijakannya berusaha untuk memajukan mutu dan kualitas pendidikan Indonesia. Peningkatan mutu pendidikan sebagai bagian yang tidak terpisahkan dari proses pengembangan sumber daya manusia, harus dilakukan secara terencana, terarah, dan intensif sehingga mampu menyiapkan bangsa Indonesia memasuki era globalisasi yang sarat dengan persaingan (Depdiknas, 2007, p.1). Beberapa kebijakan yang dilakukan adalah mendorong kepada sekolah-sekolah, baik negeri maupun swasta untuk dapat bersaing menjadi Sekolah Standar Nasional (SSN). Kebijakan lain yaitu pemerintah juga mulai merintis dan mengatur sekolah yang sudah memiliki predikat standar nasional untuk dapat dikembangkan lagi menjadi Sekolah Bertaraf Internasional (SBI). Kedua model sekolah yang dikembangkan oleh pemerintah ini tidak lain bertujuan untuk meningkatkan kualitas pendidikan di Indonesia. Dengan perintisan dan pengembangan kedua model sekolah ini diharapkan pendidikan Indonesia lebih maju dan mampu bersaing dalam era global.

Namun dalam perjalanan waktu atas berbagai pro-kontra yang timbul di masyarakat mengenai keberadaan sekolah-sekolah RSBI dan atas gugatan beberapa warga masyarakat yang menolak keberadaan sekolah RSBI, maka kemudian Mahkamah Konstitusi (MK) mengabulkan gugatan para pemohon dengan membubarkan sekolah-sekolah RSBI maupun SBI. Pembubaran itu disampaikan MK dalam sidang putusan pembatalan Pasal 50 Ayat 3 Undangundang Nomor 20 Tahun 2003 tentang Sistem Pendidikan Nasional (Sisdiknas) di Gedung MK, Jakarta, Selasa (8/1/2013). Dalam putusannya, MK menyatakan pasal yang mengatur RSBI/SBI yang berada di sekolah-sekolah pemerintah bertentangan dengan UUD 1945 dan tidak mempunyai kekuatan hukum mengikat. Dalam pertimbangannya, MK berpendapat sekolah bertaraf internasional di sekolah pemerintah itu bertentangan dengan UUD 1945, RSBI menimbulkan dualisme pendidikan, kemahalan biaya menimbulkan adanya diskriminasi pendidikan, dan pembedaan antara RSBI/SBI dengan non RSBI/SBI menimbulkan adanya kastanisasi pendidikan. Pertimbangan selanjutnya, yakni penggunaan bahasa Inggris sebagai bahasa pengantar dalam tiap mata pelajaran dalam sekolah RSBI/SBI dinilai dapat mengikis jati diri bangsa, melunturkan kebanggaan generasi mu- da terhadap penggunaan dan pelestarian bahasa Indonesia sebagai alat pemersatu bangsa. Dikatakan oleh Ketua MK bahwa pendidikan nasional tidak bisa lepas dari akar budaya dan jati diri bangsa. Penggunaan bahasa asing sebagai bahasa pengantar pada RSBI/SBI dikhawatirkan akan menjauhkan pendidikan nasional dari akar budaya dan jiwa bangsa Indonesia. (http://www.tribunnews.com)

Sistem pendidikan di sekolah-sekolah RSBI berhubungan erat dengan budaya sekolah yang diterapkan di sekolah tersebut. Jika ditilik dari persyaratan budaya sekolah di sekolah RSBI seperti yang tersebut di atas yang harus dipenuhi untuk dapat menjadi sekolah berstandar internasional adalah budaya sekolah yang memungkinkan terselenggaranya pendidikan karakter, demokratis, partisipatif dan bebas bullying. Budaya sekolah yang dimaksud adalah kegiatan dan kebiasaan yang telah disepakati bersama dalam aspek perilaku, sikap, pikiran dan pembiasaan seperti menjaga kebersihan, ketertiban lingkungan sekolah, lingkungan sekolah yang hijau, penghargaan terhadap gender, ketekunan, kerja keras, dan sebagainya (Depdiknas, 2007, p.30). Sedangkan Zamroni (2005, p.3) mengatakan bahwa budaya sekolah dapat dilihat dalam beberapa bentuk, antara lain bagaimana interaksi guru dengan siswa, dan bagaimana keterlibatan siswa dalam kegiatan sekolah. Dengan demikian dapat diambil kesimpulan bahwa setiap interaksi yang terjadi pada keseluruhan individu dalam sebuah sekolah dapat memunculkan budaya sekolah yang akan menjadi ciri khas sekolah yang bersangkutan. Budaya sekolah yang dimaksud dalam penelitian ini adalah sebuah sistem tatanan nilai dan dinamika kegiatan yang ada dan biasa dilakukan warga sekolah yang meliputi: kolaborasi profesional, hubungan kolegial, kepercayaan diri (self determination), visi-misi, keinovatifan, komitmen, konsensus, rasa hormat, kedisiplinan, empati, bebas bullying, dan artefak fisik yang terjadi di lingkup sekolah dimana penelitian dilakukan. Tata nilai dan dinamika kegiatan tersebut tercermin dalam simbol-simbol, tradisi, kebiasaan serta cara pandang kepala sekolah, guru dan staf sekolah dan pemecahan masalah yang terbentuk dari rangkaian kegiatan/ dinamika sekolah dalam rangka pencapaian tujuan sekolah yang efektif.

Keberadaan budaya sekolah merupakan faktor penting pada sekolah-sekolah unggulan setingkat SSN dan RSBI karena aspek ini adalah aspek yang terlibat langsung dalam kese- 
harian proses pendidikan di sekolah. Deal \& Petterson (2002, p.7) mengatakan bahwa pada level apapun, semua organisasi, khususnya sekolah berusaha meningkatkan prestasinya dengan mengembangkan sebuah sistem kebersamaan dari norma, kepercayaan, nilai dan tradisinya. Kemudian sekolah mulai menanamkan tradisi tersebut pada cita-cita, tujuan, dan semangat. Dijelaskan pula bahwa tanpa kekuatan, budaya yang positif, sekolah akan kesulitan dan tutup. Budaya sekolah memiliki peran penting dalam penanaman teladan dan peningkatan prestasi sekolah. Pendapat di atas kemudian dikuatkan pula oleh Hoy \& Miskel (2005, p.13) menyebutkan bahwa budaya sekolah yang baik akan meningkatkan prestasi dan motivasi siswa.

Faktor-faktor yang mempengaruhi budaya sekolah adalah hubungan erat hangat dari warga sekolah dan kejelasan serta kekonsistenan pelaksanaan kebijakan program-program sekolah. Busher (2006, p.98) menjelaskan bahwa sebuah budaya sekolah diwujudkan melalui hubungan yang didorong antara siswa dan guru, serta antara siswa, dengan pendekatan khusus dalam kegiatan belajar mengajar. Mengembangkan budaya di sekolah sangat berguna untuk memupuk hubungan interpersonal yang positif berdasarkan nilai-nilai bersama antara orang-orang yang bekerja sama.

Jika ditilik dari kajian teori di atas maka jelas terdapat perbedaan budaya dari kedua sekolah tersebut. Pada SDSN budaya sekolah yang dikembangkan adalah budaya sekolah yang berpusat pada pengembangan peserta didik lingkungan belajar yang kondusif, penekanan pada pembelajaran, profesionalisme, harapan tinggi, keunggulan, respek terhadap setiap individu warga sekolah; keadilan, kepastian, budaya korporasi atau kebiasaan bekerja secara kolaboratif/kolektif, kebiasaan menjadi masyarakat belajar, wawasan masa depan (visi) yang sama, perencanaan bersama, kolegialitas, dan tenaga kependidikan sebagai pembelajar. Sedangkan pada SD RSBI budaya sekolah yang dikembangkan adalah (1) proses pendidikan berpusat pada pengembangan peserta didik, lingkungan belajar yang kondusif, penekanan pada PAKEM, profesionalisme, harapan tinggi, keunggulan, saling peduli dan menghargai antar warga sekolah; dan (2) adanya keadilan, kasih sayang, budaya kebiasaan bekerja secara kolaboratif dan bekerja dalam tim, kebiasaan menjadi masyarakat belajar, visi yang sama, perencanaan bersama, kolegialitas, tenaga kependidikan sebagai pembelajar, pemberdayaan ber- sama, dan kepemimpinan transformatif dan partisipatif (Depdiknas, 2007, p.19). Berdasarkan perbandingan teoritis di atas, terdapat beberapa aspek budaya sekolah dari SD RSBI yang lebih unggul dan tidak terdapat pada budaya sekolah SDSN. Aspek budaya sekolah tersebut adalah: (1) penekanan pembelajaran aktif, kreatif, efektif, inovatif dan menyenangkan (PAKEM), (2) pemberdayaan bersama, (3) kepemimpinan transformatif, (4) kepemimpinan partisipatif. Menilik dari permasalahan di atas, maka penelitian ini mencoba untuk mengungkap bagaimana perbedaan budaya sekolah di SDSN dan SD Eks RSBI di wilayah Daerah Istimewa Yogyakarta.

Untuk mengukur seberapa besar perbedaan budaya sekolah di antara SDSN dan SD Eks RSBI, maka digunakan alat ukur tersebut triage survey yang meliputi: kolaborasi profesional, hubungan kolegial, dan self determination staf sekolah (Wagner, 2006, p.42). Selain mempergunakan alat ukur di tersebut juga dipergunakan beberapa aspek budaya sekolah yang perlu diteliti yaitu sebagai berikut: visimisi, keinovatifan, komitmen, rasa hormat, disiplin, empati, bebas bullying, dan artefak fisik (Depdiknas, 2007, p.5)

Berdasarkan kajian teoritis di atas maka dapat ditarik hipotesis sebagai berikut: terdapat perbedaan budaya sekolah yang signifikan antara SDSN dengan SD Eks RSBI, dimana budaya sekolah SD Eks RSBI lebih baik dari pada budaya sekolah di SDSN DIY.

\section{Metode}

Jenis Penelitian

Penelitian ini menggunakan pendekatan kuantitatif dengan jenis penelitian komparasi.

\section{Target/Subjek Penelitian}

Penelitian dilaksanakan di SDSN dan SD Eks RSBI yang ada di Daerah Istimewa Yogyakarta yang meliputi 13 SDSN dan 5 SD Eks RSBI di DIY. Keseluruhan populasi dari staf SDSN adalah 797 dan SD Eks RSBI adalah sebanyak 155 staf. Untuk menarik sampel dalam polulasi tersebut digunakan Tabel Krejcie sehingga diperoleh sampel untuk SDSN sebanyak 256 staf dan SD Eks RSBI sebanyak 116 orang. Kemudian digunakan teknik proportional sampling untuk menentukan besaran sampel dari masing-masing kabupaten/kota yang ada di DIY. 


\section{Waktu Penelitian}

Waktu penelitian adalah pada bulan Februari dan Maret tahun 2013.

Teknik Pengumpulan Data.

Teknik pengumpulan data dalam penelitian ini menggunakan teknik angket/kuesioner yang dibagikan kepada sampel terkait (staf SDSN dan SD Eks RSBI DIY). Kuesioner menggunakan lembar penyataan jawaban dengan skor nominal 1,2,3 dan 4 dengan gradasi jawaban sangat sering, sering, jarang dan tidak pernah.

\section{Instrumen Penelitian}

Instrumen dalam penelitian ini diangkat dari kisi-kisi mengenai aspek budaya sekolah yang meliputi: kolaborasi profesional, hubungan kolegial, self determination, visi-misi, inovatif, komitmen, konsensus, hormat, disiplin, empati, bebas bullying, dan artefak fisik. Instrumen penelitian diuji validitas menggunakan validitas konstrak dari ahli. Uji reliabilitas dilakukan dengan metode Alpha Cronbach, diperoleh nilai alpha cronbach sebesar 0,806 pada 54 item soal yang berarti instrumen sudah reliabel.

Teknik Analisis Data

Penelitian ini menggunakan teknik analisis data secara univariat, dan bivariat melalui teknik uji-t 2 sampel independen untuk menguji hipotesis. Uji hipotesis yang digunakan adalah uji hipotesis satu sisi (one-sided atau one-tailed test) untuk sisi atas (lower tailed), dengan hipotesis:

$$
\begin{aligned}
& \mathrm{H}_{1}: \mu_{1}<\mu_{2} \mathrm{H}_{0}: \mu_{1}-\mu_{2} \geq \\
& \mathrm{H}_{0}: \mu_{1} \geq \mu_{2} \text { atau } \mathrm{H}_{1}: \mu_{1}-\mu_{2}<0
\end{aligned}
$$

Adapun kriteria pengujian hipotesis untuk menolak atau tidak menolak $H o$ berdasarkan $P$-value adalah sebagai berikut: (1) Jika $P$-value $<\alpha$ maka $\mathrm{H}_{0}$ ditolak. Artinya apabila $P$-value $<\alpha$ maka hipotesis yang mengatakan bahwa "Tidak ada perbedaan signifikan antara budaya sekolah di SDSN dan SD Eks RSBI DIY" ditolak; (2) Jika $P$-value $\geq \alpha$ maka $\mathrm{H}_{0}$ tidak dapat ditolak. Artinya, apabila $P$-value $\geq$ $\alpha$ maka hipotesis yang mengatakan bahwa "Tidak ada perbedaan signifikan antara budaya sekolah di SDSN dan SD Eks RSBI DIY" diterima.

\section{Hasil Penelitian dan Pembahasan}

Hasil Penelitian

Melalui uji-t dua sampel independen, SPSS melakukan uji hipotesis Levene's Test untuk mengetahui apakah asumsi kedua variance sama besar terpenuhi atau tidak terpenuhi dengan hipotesis: $\mathrm{H}_{0}: \sigma_{1}{ }^{2}=\sigma_{2}{ }^{2}$ terhadap $\mathrm{H}_{1}: \sigma_{1}{ }^{2} \neq$ $\sigma_{2}^{2}$ dimana $\sigma_{1}{ }^{2}=$ variance grup 1 dan $\sigma_{2}{ }^{2}=$ variance grup 2. Dari hasil Levene's Test didapat $p$-value $=0,908$ lebih besar dari $\alpha=0,05$ sehingga $\mathrm{H}_{0}: \sigma_{1}{ }^{2}=\sigma_{2}{ }^{2}$ tidak dapat ditolak. Dengan kata lain asumsi kedua varians sama besar (equal variances assumed) terpenuhi.

Kemudian karena hasil Levene's Test di atas menyatakan bahwa asumsi kedua variance sama besar (equal variances assumed) terpenuhi; maka digunakan hasil uji-t dua sampel independen dengan asumsi kedua variance sama (equal variances assumed) untuk hipotesis $\mathrm{H}_{0}: \mu_{1} \geq \mu_{2}$ terhadap $\mathrm{H}_{1}: \mu_{1}<\mu_{2}$ yang memberikan nilai $\mathrm{t}=-0,610$ dengan derajat kebebasan $n_{1}+n_{2}-2=256+(116-2)=370$ dan $p$-value $(2-$ tailed $)=0,542$. Karena penelitian ini menggunakan uji hipotesis satu sisi (one tailed) $\mathrm{H}_{1}: \mu_{1}$ $<\mu_{2}$, maka nilai $p$-value (2-tailed) harus dibagi dua menjadi $=\frac{0,542}{2}=0,271$ karena $p$-value $=$ 0,271 lebih besar dari $\alpha=0,05$ maka $\mathrm{H}_{0}: \mu_{1} \geq$ $\mu_{2}$ tidak dapat ditolak. Sehingga dapat disimpulkan bahwa tidak ada perbedaan signifikan antara budaya sekolah antara SDSN dan SD Eks RSBI di DIY. Dengan kata lain, hipotesis awal bahwa ada perbedaan signifikan antara budaya sekolah SDSN dan SD Ek RSBI di DIY dimana SD Eks RSBI lebih baik, ditolak. Maka disimpulkan bahwa tidak ada perbedaan budaya sekolah SDSN dan SD Eks RSBI DIY yang signifikan. Hasil perhitungan ini menunjukkan bahwa meskipun kedua sekolah berbeda dalam hal status yakni SDSN dan SD Eks RSBI, budaya sekolah dalam keseharian tidak jauh berbeda antarkelompok. Dengan kata lain, standar nasional dan rintisan sekolah bertaraf internasional di SD DIY secara umum tidak berdampak pada tingginya budaya sekolah yang terbentuk. Berikut ini adalah tabel hasil uji-t: 
Tabel 1. Uji-t Mean SDSN dan SD Eks RSBI

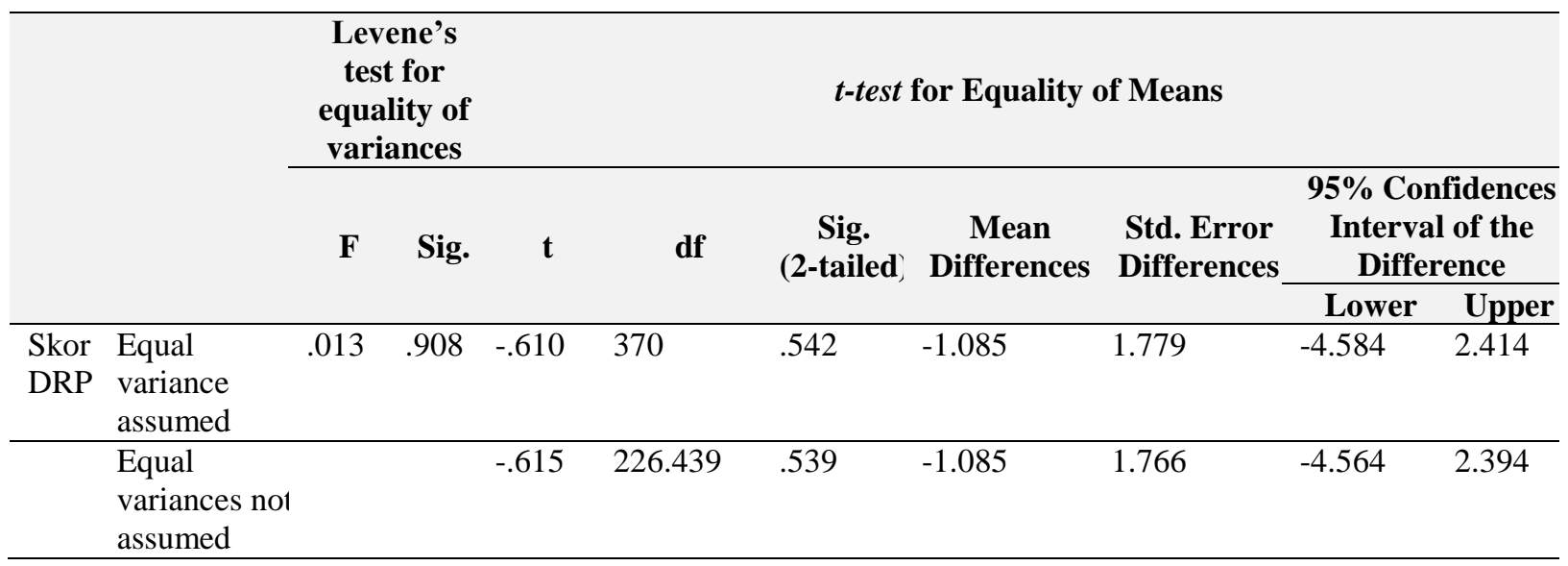

Pembahasan

Analisis dan pengujian data di atas telah memperlihatkan bahwa secara keseluruhan satu provinsi DIY, tidak terdapat perbedaan yang signifikan antara budaya sekolah SDSN dengan budaya sekolah di SD Eks RSBI. Hal ini terlihat dari jumlah purata (mean) skor budaya sekolah di SD Eks RSBI yang lebih tinggi namun tidak jauh terpaut dengan purata skor budaya sekolah di SDSN. Purata (mean) SD Eks RSBI adalah sebesar 176,78 sedangkan purata skor budaya sekolah SDSN adalah 175,70. Dengan selisih yang hanya 1,08 dan dengan perhitungan uji-t signifikansi diperoleh bilangan $p$-value $=0,271$ lebih besar dari $\alpha=0,05 \mathrm{ma}$ ka $H_{0}: \mu_{1} \geq \mu_{2}$ tidak dapat ditolak. Sehingga dapat disimpulkan bahwa tidak ada perbedaan signifikan antara budaya sekolah SDSN dan SD Eks RSBI di DIY.

Tidak terdapatnya perbedaan yang signifikan antara budaya sekolah SDSN dan SD Eks RSBI secara keseluruhan DIY tentu harus dikaji lebih lanjut. Berikut merupakan paparan analisis perbedaan aspek-aspek dalam budaya sekolah antara SDSN dan SD Eks RSBI di DIY. Pada paparan hasil penelitian diperoleh informasi bahwa tidak terdapat perbedaan budaya sekolah secara signfikan antara SDSN dengan SD Eks RSBI DIY. Penyebab dari tidak adanya perbedaan yang signifikan antara budaya sekolah SDSN dengan SD Eks RSBI akan dikaji lebih jauh berdasarkan teori dan fakta empiris pada saat penelitian berlangsung. Penyebab pertama yaitu tentang masa kerja para staf di SD Eks RSBI. Berdasarkan data responden yang diperoleh, bahwa $40 \%$ responden dari SD Eks RSBI merupakan guru/staf yang memiliki masa kerja baru 0-5 tahun di SD Eks RSBI. Hal ini berbeda dari SDSN yang staf bermasa kerja 0-5 tahun hanya sebanyak 20\%. Artinya bahwa skor budaya sekolah SD Eks RSBI yang tidak jauh berbeda dengan SDSN dapat disebabkan karena faktor staf yang masih belum berpengalaman/ masih bermasa kerja 0-5 tahun. Sejalan dengan yang diungkapkan oleh Reeves (2009, p.38) bahwa salah satu hal yang harus dilakukan dalam perubahan budaya sekolah yang baik (konteks sekolah RSBI) adalah perubahan budaya sekolah yang memerlukan perhatian pribadi tanpa henti kepada staf yang belum berpengalaman dari pihak kepala sekolah. Maka diperlukan penelitian lebih jauh mengenai seberapa maksimal usaha kepala sekolah di SD Eks RSBI dalam membina dan mengawasi para stafnya yang baru bermasa kerja 0-5 tahun tersebut.

Selain dikarenakan hal di atas, penyebab kedua adalah rendahnya skor rerata budaya sekolah di SD Eks RSBI. Jika ditelusur dari analisis masing-masing kabupaten/kota, ada dua kabupaten yang memiliki SD Eks RSBI dengan skor budaya sekolah lebih rendah daripada SDSN. Kedua kabupaten tersebut adalah Kabupaten Bantul dan Kulon Progo.

Pada kabupaten Bantul skor budaya sekolah SD Eks RSBI adalah 168,70 sementara skor SDSN yaitu 178,21. Dengan selisih skor yaitu 9,51 maka perbedaan budaya sekolah antara SDSN dengan SD Eks RSBI adalah signifikan. Ini ditandai dengan nilai hitung $p$-value sebesar 0,02 lebih kecil dari nilai $\alpha=0,05$. Pada kajian teori telah dijelaskan bahwa terdapat dua faktor yang mempengaruhi budaya sekolah. Kedua faktor tersebut yaitu hubungan erat dan hangat dari warga sekolah serta kejelasan dan kekonsistenan pelaksanaan kebijakan dan program-program sekolah (Busher, 2006, p.98). 
Jika dihubungkan dengan teori, ditemukan bahwa penyebab rendahnya skor budaya sekolah di SD Eks RSBI Bantul adalah karena kekurangeratan hubungan antarwarga sekolah. Hal ini ditandai dengan analisis empiris pada saat penelitian dilaksanakan, banyak guru yang minta supaya identitas pengisi lembar angket disembunyikan atau tidak dinampakkan. Bahkan ada salah satu guru yang mengatakan kepada peneliti bahwa guru tersebut takut jika sampai data pengisi kuesioner diketahui oleh kepala sekolah karena rawan. Ini mengindikasikan bahwa keterbukaan dan keeratan antarwarga sekolah di SD tersebut kurang terbangun sehingga menyebabkan budaya sekolah di SD Eks RSBI Bantul lebih rendah dari SDSN di Bantul.

Penyebab kedua adalah lemahnya konsistensi pelaksanaan budaya sekolah dikarenakan program RSBI baru dilaksanakan di SD Manunggal selama 4 tahun. Waktu 4 tahun belumlah cukup untuk membiasakan budaya sekolah positif yang ada di SD RSBI. Guru-guru maupun para staf sekolah memerlukan tahap penyesuaian untuk dapat melaksanakan tuntutan budaya positif di sekolah rintisan standar internasional. Tuntutan diberlakukannya menjadi sekolah rintisan internasional belum sepenuhnya dipahami oleh semua staf yang terlibat di sekolah. Hal ini menyebabkan para staf kurang paham dengan apa yang sebenarnya ingin dituju dari sekolah berstandar internasional. Seperti apa yang diungkapkan oleh Petterson (2002, p.10) bahwa budaya sekolah yang selama ini terbentuk dapat mempengaruhi fokus staf dalam bekerja, bagaimana staf mengidentifikasi sekolah (komitmen), bagaimana para staf bekerja keras (motivasi), dan sejauh mana para staf dapat mencapai tujuan. Pengaruh-pengaruh budaya lama yang masih terbawa selama masa transisi 4 tahun masih terbawa pada kebiasaan di sekolah. Akibatnya meski dengan status RSBI namun budaya sekolah masih sama dengan taraf SDSN.

Penyebab selanjutnya yang mempengaruhi tidak adanya perbedaan signifikan antara budaya sekolah SDSN dan SD Eks RSBI di DIY adalah karena lebih rendahnya budaya sekolah SD Eks RSBI daripada budaya sekolah SDSN di Kabupaten Kulon Progo. Jika ditilik dari hasil penelitian diperoleh informasi bahwa jumlah skor rerata budaya sekolah SDSN Kulon Progo adalah sebesar 182,81; sedangkan skor budaya sekolah SD Eks RSBI Kulon Progo adalah 167,16. Berdasarkan data tersebut terdapat selisih sebesar 15,65; dengan selisih tersebut kemudian dilakukan uji-t dan diperoleh nilai $p$-value 0,0005 . Karena nilai $p$-value lebih kecil dari nilai $\alpha=0,05$ maka hipotesis awal diterima, yaitu ada perbedaan signifikan dimana budaya sekolah SDSN di Kabupaten Kulon Progo lebih baik daripada SD Eks RSBI. Rendahnya budaya sekolah di SD Eks RSBI Kulon Progo disebabkan karena faktor kekurangeratan hubungan antarwarga di sekolah tersebut. Ini dapat dilihat dari analisis data yang diperoleh, jumlah skor aspek hubungan kolegial adalah 408 dengan rerata 3,4 lebih rendah daripada skor aspek yang lain. Hubungan kolegial antarstaf di SD RSBI sangat penting bagi terbentuknya budaya sekolah yang positif. Seperti yang diungkapkan oleh Deal \& Petterson (2009, p.11) bahwa sekolah yang baik lebih banyak menyediakan ruang untuk saling berbagi dan mengedepankan norma kolegialitas dan bekerja kolaboratif para stafnya. Jika hal tersebut masih lemah, maka yang terjadi adalah budaya sekolah juga menjadi lemah. Barr (2009, p.768) dalam penelitiannya mengatakan bahwa budaya sekolah yang baik dapat menciptakan kebijakan-kebijakan yang baru. Sekolah yang efektif memiliki budaya akademik yang tinggi, mewadahi misi bersama antarstaf guru dan administrator, menciptakan ras keberhasilan pada diri siswanya, dan persepsi lingkungan yang aman bagi proses kegiatan belajar-mengajar.

Berikut ini ditunjukkan perbedaan masing-masing aspek budaya sekolah antara SDSN dan SD Eks RSBI DIY: 


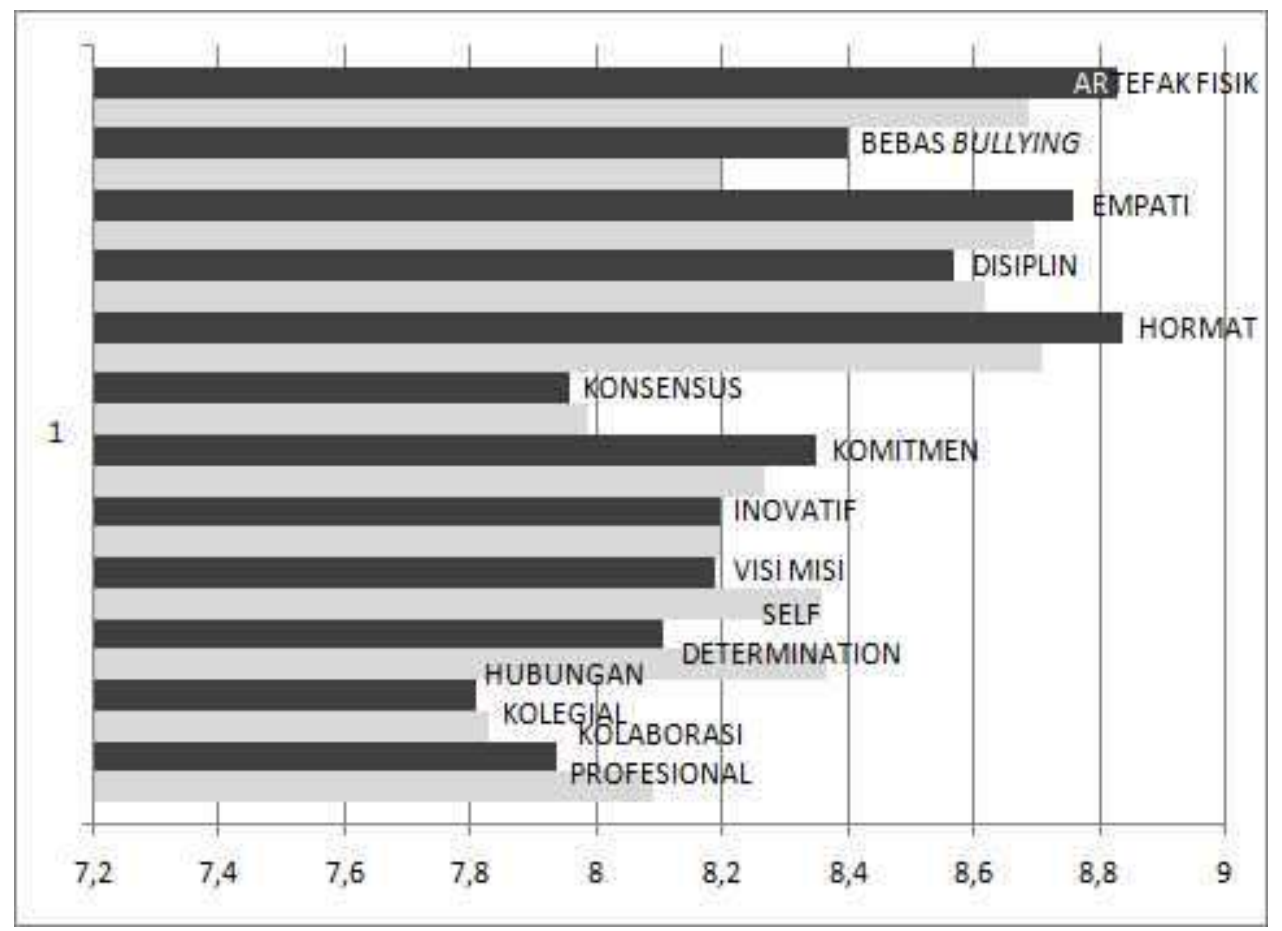

Gambar 1. Perbedaan Skor Aspek Budaya Sekolah di SDSN dan SD Eks RSBI DIY.

Di bawah ini akan dibahas mengenai perbedaan masing-masing aspek berdasarkan tabel di atas:

\section{Aspek Kolaborasi Profesional (Professional Collaboration)}

Aspek kolaborasi profesional dalam penelitian ini difokuskan pada pola kerjasama antara guru, kepala sekolah dan warga sekolah dalam permasalahan kurikulum, strategi mengajar dan inovasi pendidikan di sekolah. Pada penelitian ini diperoleh hasil bahwa persentase skor budaya sekolah aspek kolaborasi profesional di SDSN yaitu 8,09\% lebih tinggi dari pada persentase skor SD Eks RSBI dengan skor $7,94 \%$. Keduanya memiliki selisih $0,15 \%$ dimana SDSN lebih unggul. Lebih tingginya skor budaya sekolah SDSN menarik untuk dibahas lebih lanjut lagi. Berdasarkan data yang diperoleh dari responden dalam penelitian ini, sebanyak 131 staf SDSN atau 51,2\% merupakan staf berpendidikan $\mathrm{S} 1$ dan staf berpendidikan S2 hanya 1 orang atau sejumlah $0,39 \%$. Sedangkan dari SD Eks RSBI sebanyak 73 staf atau sebanyak $63 \%$ berpendidikan S1 dan 6 orang atau 5,2\% berpendidikan S2. Jika ditilik dari kualifikasi pendidikan yang berhubungan dengan keprofesionalitasan staf, maka seharusnya SD Eks RSBI skor rerata aspek kolaborasi profesionalnya lebih tinggi daripada SDSN karena berdasarkan persentase kualifikasi pendidikan guru/staf SD Eks RSBI lebih banyak.
Akan tetapi pada penelitian ini yang terjadi justru sebaliknya, aspek kolaborasi profesional di SDSN lebih tinggi daripada SD Eks RSBI. Kontradiksi ini tentu menimbulkan pertanyaan lanjutan, apakah kualifikasi pendidikan guru/ staf benar-benar dapat mempengaruhi budaya kolaborasi profesional guru/staf di sekolah? Apakah dengan berpendidikan tinggi kemudian guru/staf sekolah dapat mengembangkan serta saling berbagi permasalahan dan berdiskusi memecahkan persoalan mengenai tugasnya di sekolah? Jika menilik dari hasil penelitian pada salah satu jurnal internasional yang membahas tentang budaya kolaborasi profesional guru/staf di sekolah maka didapat kesimpulan bahwa budaya sekolah kolaboratif dapat memberikan banyak keuntungan. Berbagai keuntungan itu diantaranya mengurangi isolasi guru, memberikan dukungan sosial dan emosional pada guru, memberikan pengembangan peluang bagi keprofesionalitasan guru, dan mendorong hubungan yang lebih erat dengan berbagai pemangku kepentingan (Dickerson, 2011, p.1). Maka dapat disimpulkan bahwa tingginya kualifikasi pendidikan tidak selalu berpengaruh terhadap hubungan kolaborasi, justru hubungan kolaborasi akan terbangun dari pengaruh budaya sekolah yang baik.

\section{Aspek Hubungan Kolegial}

Budaya sekolah aspek hubungan kolegial dalam penelitian ini berfokus pada hu- 
bungan non formal antar sesama staf/guru, kepala sekolah dan karyawan. Hubungan kolegial dapat dimisalkan saling bertukar pikiran, bertukar pengalaman, saling mengunjungi, acara acara pertemuan sesama staf di luar jam kerja, dsb. Hubungan kolegial yang erat atau tinggi intensitasnya akan membuat staf/guru merasa nyaman dan menikmati pekerjaannya. Dalam tabel di atas perbedaan skor aspek hubungan kolegial di antara staf SDSN dan SD Eks RSBI tidak jauh berbeda, hanya selisih $0,02 \%$. Pada SDSN persentase skor hubungan kolegial adalah 7,83\% sedangkan pada SD Eks RSBI persentasenya 7,81\%. Dari data tersebut dapat disimpulkan bahwa hubungan kolegial diantara guru/staf SDSN dengan SD Eks RSBI tidak jauh berbeda. Namun yang menarik adalah hubungan kolegial di SDSN lebih tinggi daripada SD Eks RSBI. Sama halnya dengan aspek budaya kolaborasi profesional (professional collaboration) yang telah dipaparkan sebelumnya, budaya hubungan kolegial (affiliative colegiality) di SDSN lebih tinggi daripada SD Eks RSBI. Masih menjadi pertanyaan besar, padahal persentase kualifikasi pendidikan guru/ staf SD Eks RSBI lebih banyak daripada SDSN. Dalam sebuah jurnal penelitian kualitatif terungkap bahwa intensifikasi pekerjaan dan kebijakan pemerintah menggalakkan manajemen berbasis sekolah merupakan akar dari berbagai permasalah di sekolah. Artikel tersebut menggunakan pendekatan kualitatif dari studi stres guru utama untuk meneliti hubungan staf di sekolah dasar. Hasilnya diperoleh bahwa intensifikasi pekerjaan guru berperan dalam mengikis hubungan staf yang positif, juga berdampak pada perubahan hubungan kepercayaan modernitas tinggi yang membentuk hubungan sosial-kepercayaan yang berpendidikan tinggi, dan berdampak negatif pada fisik dan emosional kesejahteraan dan hubungan profesional kolegial mereka (Troman, 2000, p.331). Hasil penelitian pada jurnal tersebut menguatkan hasil penelitian pada tesis ini, yaitu pada aspek kolegialitas SD Eks RSBI lebih rendah dari pada SDSN dikarenakan banyaknya tuntutan atau intensifikasi pekerjaan guru yang dapat berdampak pada rendahnya hubungan kolegial diantara para staf.

\section{Aspek Kebulatan Tekat (Self Determination)}

Budaya sekolah dalam aspek kebulatan tekat pada penelitian ini berfokus pada kebulatan tekat dalam diri staf pada usaha perbaikan dan kemajuan sekolah. Kebulatan tekat dapat diukur dari kesegeraan mengambil tindakan terhadap suatu keputusan dan tidak menundanunda atau menunggu perintah atasan, sikap saling menghargai, kerjasama mencari solusi dan bukan menyalahkan. Pada tabel di atas perbedaan persentase skor budaya sekolah aspek self determination cukup banyak perbedaannya. Pada SDSN dengan persentase skor yaitu $8,37 \%$ sedangkan pada SD Eks RSBI hanya 8,11\% atau ada selisih $0,26 \%$ dimana skor SDSN lebih tinggi. Perbedaan kebulatan tekad staf SDSN dan SD RSBI ini kemungkinan disebabkan karena memang program RSBI dengan segala aturannya bukan timbul dari kesadaran para staf untuk menuju standar internasional, melainkan adalah amanat sebuah tuntutan UU yang harus dilaksanakan (saat sebelum UU tentang RSBI dihapus). Dalam UU itu disebutkan bahwa daerah kabupaten/kota sekurang-kurangnya harus memiliki satu sekolah yang berstandar internasional pada setiap jenjang pendidikan dasar dan menengah. Dalam menerjemahkan UU ini kemudian masing-masing pemerintah daerah berlomba memenuhi tuntutan tersebut dan memilih salah satu sekolah untuk dijadikan SD RSBI. Tuntutan atas disematkannya label RSBI diantaranya harus menggunakan bahasa asing dalam bahasa pengantar dan beberapa tuntutan lain tidak timbul dari kesadaran diri para staf sekolah yang bersangkutan. Hal ini dimungkinkan akan menyebabkan rendahnya kebulatan tekad staf RSBI untuk menjalani program tuntutan RSBI. Berbeda halnya dengan SDSN yang tidak sama tuntutannya dari SD RSBI. Programprogram yang menunjang kemajuan pendidikan di SDSN lahir dari keinginan para stafnya untuk mempertahankan label SSN nya.

\section{Aspek Visi dan Misi}

Aspek visi dan misi yang menjadi fokus dalam penelitian ini antara lain adalah pelaksanaan tugas sehari-hari para staf di sekolah yang ditujukan guna mencapai visi dan misi sekolah. Pada tabel perbedaan aspek visi dan misi di atas terlihat bahwa visi dan misi SDSN lebih tinggi daripada visi dan misi SD Eks RSBI. Terlihat bahwa persentase skor SDSN sebesar 8,36\% sedangkan SD Eks RSBI sebesar $8,19 \%$ yang berarti terdapat selisih $0,17 \%$. Pada aspek yang keempat ini SDSN kembali lebih unggul daripada SD Eks RSBI. Dalam penelitian ini diberikan pernyataan mengenai beberapa hal berikut, yaitu: intensitas para staf dalam memahami visi dan misi sekolah dan kesesuaian aktivitas staf dengan visi 
misi sekolah. Rendahnya skor visi dan misi SD Eks RSBI dibandingkan dengan SDSN dapat disebabkan karena para staf belum paham betul akan visi dan misi sekolahnya yang berstandar internasional. Banyak penafsiran berstandar internasional hanya sekedar penggantian buku teks dengan buku teks asing berbahasa Inggris atau sekedar mengajar dengan bahasa Inggris. Padahal hakekat sebenarnya dari sekolah berstandar internasional adalah sekolah itu tidak kalah saing dengan sekolah-sekolah di luar negeri. Untuk bisa bersaing dengan sekolah luar negeri tentu membutuhkan visi dan misi yang jelas dan terarah. Rendahnya skor visi dan misi SD Eks RSBI menunjukkan bahwa visi dan misi sekolah SD RSBI belum terarah dengan jelas kemana tujuan sekolah tersebut. Ini menjadi koreksi bagi pemegang kebijakan baik di tingkat lokal maupun nasional. Pembubaran RSBI bisa juga dimungkinkan karena kajian dari aspek ini.

\section{Aspek Keinovatifan}

Pada aspek keinovatifan staf dalam menjalankan tugasnya, diperoleh hasil penelitian bahwa persentase skor antara SDSN dengan SD Eks RSBI tidak ada perbedaan. Skor keduanya adalah $8,20 \%$. Keinovatifan yang menjadi fokus penelitian ini antara lain adalah keberanian mengambil resiko, dukungan terhadap inovasi-inovasi pendidikan di sekolah, dan kegiatan perbaikan dan peningkatan mutu sekolah berdasarkan evaluasi, monitoring dan penelitian. Tidak terdapatnya perbedaan dalam skor ini bukan berarti sesuatu yang wajar adanya. Menjadi sebuah pertanyaan bagi sekolah rintisan standar nasional namun tingkat keinovatifan tidak ada perbedaan dengan SDSN. Secara logi$\mathrm{ka}$, amanat dari program standar internasional adalah supaya sekolah mampu mengadopsi nilai-nilai, sumber-sumber belajar, media belajar, bahasa pengantar universal supaya dapat bersaing dengan dunia pendidikan internasional. Kemudian hasil adopsi tersebut menjadi sebuah kreasi inovasi-inovasi pendidikan yang diimplementasikan di sekolah. Namun 5 tahun berjalan program rintisan sekolah berbasis internasional belum mampu mendapatkan skor setidaknya lebih tinggi dari skor keinovatifan SDSN. Meskipun begitu pembahasan dan analisis ini hanya sebatas empiris dan dugaan berdasarkan fakta perbandingan skor yang belum bisa menggambarkan penuh apa yang terjadi di SD Eks RSBI maupun di SDSN. Maka diperlukan penelitian lebih lanjut.

\section{Aspek Komitmen}

Aspek keenam yang menjadi fokus penelitian adalah budaya sekolah dalam hal komitmen para staf untuk bersama-sama memajukan mutu pendidikan di tempat kerjanya. Diberikan 3 pernyataan tentang komitmen di antaranya adalah artefak/tulisan mengenai komitmen memajukan sekolah, komitmen pimpinan dan staf dalam menjalankan kedisiplinan/sanksi, dan kesadaran akan komitmen pribadinya di sekolah. Pada aspek komitmen diperoleh hasil bahwa persentase skor SD Eks RSBI lebih tinggi daripada SDSN. Perbedaan di antara keduanya hanya terpaut $0,08 \%$, dimana skor SD Eks RSBI adalah 8,35\% sedangkan SDSN dengan skor $8,27 \%$. Hasil penelitian pada aspek komitmen ini kontradiktif dengan hasil skor aspek visi dan misi yang telah menjadi pembahasan sebelumnya. Meskipun SD Eks RSBI dalam hal visi dan misi lebih rendah daripada SDSN, namun pada aspek komitmen memajukan sekolah ternyata lebih tinggi daripada SDSN. Dukungan moril serta dana dari masyarakat dan pemerintah daerah dimungkinkan menjadi penyebab tingginya komitmen pimpinan dan staf untuk memajukan mutu sekolahnya. Tingginya komitmen ini juga jika dihubungkan dengan kualifikasi pendidikan pimpinan dan stafnya, SD RSBI memiliki pimpinan minimal S2. Berdasarkan data responden sebanyak 73 orang atau $63 \%$ responden dari RSBI merupakan tenaga berkualifikasi S1 serta ditilik dari lama mengajar/bertugas ternyata sebagian besar guru/staf di RSBI sebanyak 46 responden atau sekitar $40 \%$ merupakan tenaga yang baru bekerja 0-5 tahun. $40 \%$ tenaga-tenaga baru ini masih dalam upaya menunjukkan kinerjanya, melaksanakan performa maksimal dalam ketugasannya menjadi guru/staf di SD Eks RSBI. Data tersebut mendukung tingginya komitmen para staf SD RSBI untuk meningkatkan mutu pendidikan di sekolah. Tenaga yang baru dan berpendidikan tinggi dapat menjadi suntikan segar bagi upaya peningkatan mutu pendidikan.

Pernyataan di atas senada dengan hasil penelitian dari Khosrow (2012, p.6) yang mendapatkan hasil penelitian bahwa terdapat perbedaan signifikan antara komitmen dosen perguruan tinggi di Iran dengan komitmen guru. Hasil analisis $t$-test menunjukkan bahwa terdapat perbedaan yang signifikan antara dosen dan guru (non-lecturers) dalam komitmen afektif, $\mathrm{t}$ $=7,753, \mathrm{p}>0,05$. Juga, analisis $t$-test menunjukkan ada perbedaan yang signifikan antara dosen 
dan guru (non-lectures) dalam melanjutkan keterlibatan di dalam organisasi, $\mathrm{t}=5,094, \mathrm{P}$ $<0,05$ tingkat. Perbedaan signifikan tersebut ditemukan bahwa komitmen kerja pada dosen lebih tinggi dari pada guru. Ini menunjukkan bahwa perbedaan kualifikasi pendidikan yang lebih tinggi dapat mempengaruhi tingginya komitmen bekerja. Sama halnya dengan di SD Eks RSBI yang memiliki kualitas SDM lebih baik dan kepala sekolah yang lebih tinggi kualifikasi pendidikannya menyebabkan komitmen di SD RSBI lebih baik daripada SDSN.

\section{Aspek Konsensus}

Salah satu aspek budaya sekolah yang berpengaruh terhadap kesuksesan programprogram peningkatan mutu sekolah adalah budaya konsensus. Konsensus berarti pelibatan seluruh elemen staf yang terlibat di dalam sekolah maupun partisipasi masyarakat/stake holder yang dapat mendukung kemajuan sekolah. Melalui konsensus keputusan-keputusan strategis mengenai sekolah akan mudah diterima dan dilaksanakan dengan kesadaran penuh oleh seluruh guru, staf maupun pimpinan sekolah. Pada penelitian ini diperoleh data bahwa budaya penerapan konsensus di SDSN lebih tinggi daripada di SD Eks RSBI. Hal ini terlihat dari persentase skor aspek konsensus SDSN adalah sebesar 7,99\% sedangkan di SD Eks RSBI sebesar $7,96 \%$. Perbedaan keduanya tidak jauh berbeda, hanya selisih $0,03 \%$. Lebih tingginya aspek konsensus di SDSN bisa dipengaruhi berbagai hal. Berkurangnya dominasi otorisasi keputusan dari kepala sekolah adalah salah satu penyebab tingginya konsensus. Pelibatan seluruh staf dalam pengambilan keputusan melalui musyawarah akan mendukung terlaksananya program-program sekolah. Pada penelitian ini terjadi kontradiksi dimana SD Eks RSBI yang diberi kewenangan untuk menjalin kerja sama dengan pihak luar bahkan sekolah di luar negeri sebagai sister school, namun yang terjadi justru budaya konsensusnya lebih rendah dari SDSN. Perlu penelitian lebih lanjut sejauh mana sekolah-sekolah Eks RSBI mengembangkan budaya konsensusnya. Orang-orang dalam organisasi yang sehat harus memiliki kesepakatan tentang bagaimana melakukan sesuatu dan apa yang layak dilakukan. Stabilitas antar staf sekolah dan tujuan bersama memajukan sekolah. Baik itu aspek kurikuler dan komponen instruksional, serta ketertiban dan disiplin, ditetapkan melalui konsensus. Komunikasi yang terbuka dan jujur dan ada banyak humor dan kepercayaan dan didukung peran serta pemimpin (Wagner, 2006, p.40).

\section{Aspek Hormat (Respectful)}

Aspek hormat yang menjadi fokus dalam penelitian ini adalah seputar tingkah laku, tutur kata staf, dan teladan dari seluruh warga sekolah terutama para guru dan staf SDSN dan SD Eks RSBI. Diperoleh data bahwa persentase skor SD Eks RSBI dalam aspek hormat (respectful) lebih tinggi daripada SDSN. Ini terlihat dari tabel perbedaan aspek budaya sekolah yang telah dipaparkan di atas, SD Eks RSBI dengan persentase skor yaitu 8,84\% sedangkan SDSN sebesar $8,71 \%$. Keduanya mempunyai selisih 0,13\% dimana SD Eks RSBI lebih tinggi. Data ini menarik untuk dikaji lebih lanjut, ternyata kekhawatiran banyak pihak bahwa label internasional akan membawa dampak terkikisnya budaya ketimuran siswa dan guru tidak terbukti. Bahkan SD Eks RSBI lebih tinggi skor aspek hormatnya. Para guru dan siswa meski sistem pendidikan, materi, kurikulum dan bahasa pengantar sebagian mengadopsi dari negara lain, namun budaya hormat masih tetap tinggi. Dalam sebuah jurnal penelitian, Larusso (2008, p.386) mengatakan bahwa rasa hormat antarguru dan siswa dapat meningkatkan iklim sekolah yang positif. Diperoleh hasil bahwa rasa hormat, perhatian, dukungan, dan budaya saling menghormati sesama warga sekolah dapat mengurangi gejala depresi pada warga sekolah. Melihat pentingnya aspek saling menghormati dalam budaya sekolah ini, maka sudah seharusnya sekolah-sekolah mengembangkan dan membudayakan sikap saling menghormati melalui bentuk-bentuk perhatian, dukungan, konseling kepada para siswa.

\section{Aspek Kedisiplinan}

Elemen budaya sekolah dalam aspek disiplin dalam penelitian ini adalah seputar kedisiplinan seluruh warga sekolah baik kepala sekolah, guru, staf dan siswa dalam berpakaian, kehadiran, penyelesaian tugas dan tanggung jawab, serta peraturan yang dijalankan sekolah. Dari analisis data pernyataan responden diperoleh data bahwa pada aspek kedisiplinan, SDSN lebih unggul daripada SD Eks RSBI. Hal ini bisa dicermati dari perolehan persentase skor untuk SDSN adalah sebesar 8,62\% sedangkan SD Eks RSBI sebesar 8,57\%. Keduanya memiliki selisih $0,05 \%$, selisih yang tidak terlalu jauh berbeda. Ternyata berdasarkan hasil penelitian tersebut, budaya disiplin di SDSN lebih 
baik daripada di SD Eks RSBI. Belum diketahui secara pasti penyebab lebih tingginya budaya disiplin di SDSN daripada di SD Eks RSBI. Namun dapat kita cermati di SD Eks RSBI dengan siswa dan guru pilihan yang dapat berada di sana namun terjadi kontradiksi dengan kedisiplinannya.

\section{Aspek Empati}

Aspek empati yang dimaksud dalam penelitian ini adalah kemampuan staf dan warga sekolah dalam menempatkan diri atau dapat merasakan apa yang dirasakan oleh orang lain namun tidak ikut larut dalam perasaan itu. Sikap empati perlu dimiliki oleh seluruh personil sekolah agar dalam berinteraksi dengan siapa saja dan dimana saja mereka dapat memahami penyebab dari masalah yang mungkin dihadapai oleh orang lain dan mampu menempatkan diri sesuai dengan harapan orang tersebut. Dengan sifat empati warga sekolah dapat menumbuhkan budaya sekolah yang lebih baik karena dilandasi oleh perasaan yang saling memahami. Pada hasil penelitian yang membandingkan aspek empati dari SDSN dan SD Eks RSBI, diperoleh hasil bahwa SD Eks RSBI memiliki budaya empati lebih tinggi daripada SDSN. Dengan perolehan persentase skor 8,76\%, SD Eks RSBI lebih unggul dari SDSN yang memiliki skor $8,70 \%$. Keduanya memiliki selisih 0,06 yang tidak terlalu jauh berbeda. Komitmen yang tinggi untuk mempertahankan label RSBI dengan berbagai tuntutan yang harus dipenuhi diperkirakan dapat menyebabkan tumbuhnya rasa empati dari masing-masing staf SD Eks RSBI dalam menjalankan tugasnya.

\section{Aspek Bebas Bullying/Tanpa Kekerasan}

Budaya sekolah bebas bullying yang dimaksud dalam penelitian ini adalah perilaku guru maupun siswa terhadap sesamanya apakah bebas dari kekerasan baik verbal maupun fisik. Dari hasil analisis data melalui 256 responden dari SDSN dan 116 responden dari SD Eks RSBI, diperoleh data bahwa persentase skor SDSN adalah 8,20\% sedangkan SD Eks RSBI sebesar $8,83 \%$. Menarik untuk dikaji lebih lanjut, dengan selisih $0,20 \%$ ternyata budaya bebas kekerasan di SD Eks RSBI jauh lebih baik daripada di SDSN. Ini berarti bahwa para staf dan siswa di SD Eks RSBI lebih mengedepankan nasehat daripada hukuman fisik dalam menyelesaikan masalah yang terjadi di sekolah. Jika dihubungkan dengan data responden, bahwa sebagian besar staf/guru di SD Eks RSBI adalah guru-guru muda yang idealismenya masih tinggi, berpendidikan S1 yang telah dibekali dengan ilmu humanisme dalam mendidik siswanya. Juga didukung dari input siswa SD Eks RSBI merupakan siswa-siswa pilihan karena SD Eks RSBI diberi kewenangan untuk menyeleksi siswa yang unggul dalam akademik maupun non akademik (tidak anarkis). Erickson (2004, p. 113) mengatakan bahwa budaya sekolah yang dapat meminimalkan kekerasan, intimidasi, ancaman, dan mendukung bagi perkembangan kesehatan siswa dalam budaya saling menghormati, pengakuan, pembagian tugas, dan pemulihan dapat dibangun di sekolah yang efektif. Semua usaha itu membutuhkan usaha yang sinergis dari semua warga sekolah dalam membangun perdamaian dan kekuasaan tanpa kekerasan. SD Eks RSBI dinilai sebagai sekolah yang efektif, maka wajar jika budaya sekolah bebas bullying lebih tinggi daripada SDSN.

\section{Aspek Artefak Fisik}

Budaya sekolah aspek artefak fisik dalam penelitian ini dikhususkan kepada sejauh mana sekolah menyediakan dan pengelolaan sarana dan prasarana belajar mengajar, pemasangan tulisan tulisan semboyan dan penataan lingkungan sekolah yang rapi dan bersih. Dari hasil penelitian diperoleh data bahwa SD Eks RSBI lebih unggul pada budaya sekolah artefak fisik. Dengan perolehan persentase skor $8,83 \%$, SD Eks RSBI lebih unggul dari pada SDSN dengan skor 8,63. Selisih dan perbedaannya adalah $0,14 \%$, ini berarti bahwa SD Eks RSBI lebih baik dalam menyediakan sarana dan prasarana yang dibutuhkan siswa dan guru, pemasangan semboyan dan dalam penataan lingkungan sekolah. Dengan dukungan dana dari pemerintah maupun wali murid dan masyarakat, maka SD Eks RSBI lebih baik dalam hal penyediaan, penataan, pengelolaan artefak fisik yang berupa sarana dan prasarana maupun papan-papan semboyan. Hal ini berbeda dengan SDSN yang memiliki larangan untuk memungut biaya sumbangan dari wali murid dan tidak mendapat dana alokasi khusus dari pemerintah daerah untuk meningkatkan mutu sekolah. Sehingga wajar jika SDSN lebih rendah dalam hal budaya artefak fisik daripada SD Eks RSBI. Hal ini sejalan dengan pendapat dari Wayne (2001, p.185) menyebutkan bahwa simbol yang mengekspresikan budaya sekolah biasanya digunakan untuk membantu mengidentifikasi tema budaya yang penting. Disebutkan bahwa ada tiga bentuk sistem komunikasi dari isi budaya sekolah, yaitu: 
sejarah, ikon fisik (logo, moto, dan tropi) serta ritual (upacara atau acara rutin penting yang diadakan sekolah.

Dengan demikian, berdasarkan uraian di atas dapat disimpulkan inti dari pembahasan di atas bahwa secara keseluruhan satu provinsi DIY, tidak terdapat perbedaan signifikan budaya sekolah SDSN dengan SD Eks RSBI. Namun meskipun tidak terdapat perbedaan secara signifikan antara budaya sekolah SDSN dengan SD Eks RSBI se-DIY, tetap ada perbedaan signifikan budaya sekolah antara SDSN dengan SD Eks RSBI di masing-masing kabupaten/ kota. SD Eks RSBI lebih unggul dalam budaya sekolah di Kabupaten/Kota Yogyakarta, Sleman dan Gunungkidul. Sedangkan SDSN lebih unggul dalam budaya sekolah di Kabupaten Bantul dan Kulon Progo. Selain itu terdapat pula perbedaan pada masing-masing aspek budaya sekolah yang diteliti, dimana SDSN lebih unggul pada 6 aspek budaya sekolah yaitu: kolaborasi profesional (professional collaboration), hubungan kolegial (affiliative collegiality), kepercayaan diri dan kebulatan tekad (self determination/efficacy), visi-misi, konsensus dan disiplin. Sedangkan SD Eks RSBI lebih unggul dalam 5 aspek budaya sekolah yaitu komitmen, hormat, empati, bebas bullying dan artefak fisik.

\section{Simpulan dan Saran}

Simpulan

Berdasarkan hasil analisis pada penelitian ini dapat disimpulkan bahwa: (1) tidak terdapat perbedaan budaya sekolah secara signifikan antara SDSN dan SD Eks RSBI di Daerah Istimewa Yogyakarta. Kesimpulan ini diperoleh berdasarkan perbedaan skor rata-rata budaya sekolah SDSN yaitu sebesar 175,70 sedangkan SD Eks RSBI sebesar 176,78 dengan hanya selisih 1,08. Melalui uji-t dua sampel independen diperoleh $p$-value $=0,271$ lebih besar dari $\alpha=0,05$. Dengan kata lain, hipotesis awal bahwa ada perbedaan signifikan antara budaya sekolah SDSN dan SD RSBI di DIY ditolak, (2) ditemukan perbedaan skor dari masing-masing aspek budaya sekolah di SDSN dan SD eks RSBI DIY. Aspek budaya sekolah yang lebih baik di SDSN adalah kolaborasi profesional, hubungan kolegial, self determination, visi-misi, konsensus, dan disiplin. Sedangkan aspek budaya sekolah yang lebih unggul pada SD Eks RSBI adalah aspek komitmen, hormat, empati, bebas bullying dan artefak fisik.

Saran

Saran dalam penelitian ini adalah sebagai berikut: agar para guru dan staf SDSN dan SD Eks RSBI DIY dapat berupaya baik secara pribadi maupun kolektif melatih, membiasakan, dan meningkatkan budaya sekolah yang masih lemah seperti budaya kolaborasi profesional, hubungan kolegial, konsensus dalam tugas kesehariannya di sekolah, serta selalu menjalin hubungan kerjasama yang baik dengan masyarakat sekitar; Kepala sekolah agar mendorong dan mengawasi stafnya untuk membiasakan budaya sekolah yang baik dan kuat seperti memberikan kesempatan para stafnya untuk berinovasi, mengajak berpartisipasi/berpendapat (konsensus), dan mendorong dan memberi kesempatan stafnya untuk berkolaborasi profesional; serta bagi peneliti berikutnya adalah agar melanjutkan dan memperdalam hubungan antara aspek-aspek budaya sekolah terhadap efektifitas sekolah.

\section{Daftar Pustaka}

Alasan MK membubarkan Sekolah RSBI. Diakses tanggal 8 Januari 2013 dari http://www.tribunnews.com/2013/01/08 lalasan-mk-bubarkan-sekolah-rsbi

Barr, J.J., Alessandro,H.D., \& Ann. (2009). How adolescent empathy and prosocial behavior change in the context of school culture: a two-year longitudinal study[Versi Elektronik]. Adolescence , 44, 751-772.

Busher, H. (2006). Understanding educational leadership, people, power and culture. England: McGraw-Hill Educartion

Deal, T.E. \& Peterson, K.D (2002). The shaping school culture fieldbook. San Francisco: Jossey Bass Company

(2009). Shaping school culture: pitfalls, paradoxes and promises. San Francisco: Jossey Bass.

Depdiknas. (2007). Panduan penyelenggaraan rintisan sekolah dasar bertaraf internasional. Jakarta: Direktorat Pendidikan Menengah Umum, Direktorat Pendidikan Dasar Menengah Departemen Pendidikan Nasional. 
Dickerson, M.S. (2011). Building a collaborative school culture using appreciative inquiry [Versi Elektronik]. International Refereed Research Journal, 2, 2536.

Erickson, C. L., et.al, (2004). Constructing nonviolent cultures in schools [Versi Elektronik]: The State of the Science.

Hoy, W.K \& Miskel, C.G. (2005). Educational administration: theory, research, and practise. New York: Mc Graw-Hill.

Khosrow, et.al. (2012). An empirical investigation of lectures' organizational commitment in technical and vocational colleges in Iran. Educational Research Multimedia \& Publicatios: Proquest Journal, 3, 1-10.

Petterson, K.D. (2002). Positive or negative? Journal of Staff Development, Summer, 2002. Vol. 23. No. 3
Reeves, D.B. (2009). Leading change in your school; how to conquer myths, bulid commitment, and get results. Virginia USA: Association for Supervision and Curriculum Development (ASCD)

Troman, G. (2000). Teacher stress in the lowtrust society. Taylor \& Francis Ltd. British journal of sociology of education, 3, 331-353

Wagner, C.R. (2006). The school leader's tool for assesing and improving school culture. Kentucky: Western Kentucky University

Wayne, C.R. (2006). The school leader tool for assesing and improving school culture. Kentucky: Western Kentucky University

Zamroni. (2000). Paradigma pendidikan masa depan. Yogyakarta: Bigraf Publishing 